were found to have infection when seen several years later. Excretion urography undertaken in 23 patients produced no evidence of chronic pyelonephritis. A small number showed a modest rise in blood-pressure, but none of them had infection of the urinary tract. Four patients had a positive pyrogen or steroid provocation test. In none of the group of 134 patients was there conclusive evidence of chronic pyelonephritis.

We wish to thank Professor W. A. Gillespie and Dr. S. T. Crowther for help and advice, the consultant gynaecologists for permission to use their clinical cases, and the nursing staff for their willing assistance.
RBFERENCES

Cattell, W. R., Curwen, M. P., Shooter, R. A., and Williams, D. K. (1963). Brit. med. \%., 1, 923

Fry, J., Dillane, J. B., Joiner, C. L., and Williams, J. D. (1962). Lancet, $1,1318$.

Gillespie, W. A., Lennon, G. G., Linton, K. B., and Slade, N. (1962). Brit. med. $7 ., 2,13$.

Hanley, H. G. (1963). Lancet, 1, 22.

Jackson, G. G., Dallenbach, F. D., and Kipnis, G. P. (1955). Med. Clin. N. Amer., 39, 297.

Kass, E. H. (1962). Ann. intern. Med., 56, 46.

Leather, H. M., and Hutchings, M. T. (1960). Lancet, 2, 654. Wills, M. R., and Gault, H. M. (1963). Brit. med. F., 1, 92.

Little, P. J., and de Wardener, H. E. (1962). Lancet, 1,1145 .

Lytton, B. (1961). Brit. med. ₹., 2, 547.

Pears, M. A., and Houghton, B. J.' (1959). Lancet, 2, 1167.

Pinkerton, J. H. M., Wood, C., Williams, E. R., and Calman, R. M (1961). Brit. med. F., 2, 539.

\title{
Effects of Chloroquine on Patients with Cutaneous Porphyria of the "Symptomatic" Type*
}

\author{
G. D. SWEENEY, $\dagger$ M.B., CH.B., PH.D. ; S. J. SAUNDERS, $†$ M.8., M.R.C.P., F.C.P.(S.A.) ; \\ E. B. DOWDLE, $\dagger$ M.D., M.R.C.P. ; L. EALES, $\dagger$ M.D., F.R.C.P.
}

Brit. med. F., 1965, 1, 1281-1285

First introduced as an antimalarial drug during the second world war, the 4-aminoquinoline, chloroquine, has found increasing use in the treatment of other conditions. The value of chloroquine in the treatment of chronic discoid lupus erythematosus is generally accepted and it has been used extensively for the treatment of other light-sensitive conditions, including cutaneous porphyria.

In 1954, however, Linden et al. reported " the development of porphyria during chloroquine therapy." Subsequently, various reports appeared on the use of chloroquine in porphyria; some authors claimed that the drug was beneficial, while others recorded adverse reactions. Eales (1961) reviewed these reports and recorded that serial studies had shown a marked increase in urine porphyrin excretion without coincident rise in the excretion of $\delta$-aminolaevulinic acid (A.L.A.) or porphobilinogen (P.B.G.) when chloroquine was given to a patient with cutaneous porphyria ; the patient also showed a severe constitutional disturbance. Embree (1961) reported similar findings in seven Bantu porphyric patients. Cripps and Curtis (1962), in reporting the toxic effect of chloroquine on three patients with porphyria hepatica, suggested that this drug worsened the disease.

It was thus apparent that a drug advocated by some for the treatment of cutaneous porphyria might, in fact, be harmful.

There has been an unfortunate lack of unanimity regarding classification and terminology of the diseases of porphyrin metabolism. This fact, together with the omission from publications of such vital data as faecal porphyrin excretion, and the status of other members of patients' families, has led to confusion. At an International Conference on the Porphyrias held in Capetown in 1963 (Eales et al., 1963) the following classification was agreed to by delegates from Great Britain, the United States, France, Sweden, and South Africa:

* Requests for reprints of this paper should be addressed to Professor L. Eales, Department of Medicine, University of Capetown, Observatory, Cape.

t Department of Medicine, University of Capetown and Groote Schuur Hospital, Capetown, South Africa.

\section{The Hepatic Porphyrias}

1. Acute intermittent porphyria (pyrroloporphyria, Swedish genetic porphyria).

2. Variegate porphyria (protocoproporphyria, South African genetic porphyria).

3. The cutaneous porphyrias (purely cutaneous presentation): (a) Hereditary type. (b) Possibly genetically predisposed type(s)-for example, the form associated with alcoholism (constitutional, symptomatic porphyria, porphyria cutanea tarda). (c) Acquired type(s)-for example, hexachlorobenzene poisoning.

\section{The Erythropoietic Porphyrias}

1. Congenital erythropoietic porphyria.

2. Erythropoietic protoporphyria.

Discussion of criteria for diagnosis of these various forms of porphyria will be found in the proceedings of the conference referred to above.

Study of the literature suggested that almost all reported adverse reactions to chloroquine had occurred in patients suffering from type I $3 b$-namely, "symptomatic porphyria." Possible exceptions to this are Case 3 of Cripps and Curtis (1962), the case of Woods et al. (1958), and one of the cases reported by Teodorescu et al. (1959).

In this paper we report the effects of chloroquine on a total of nine patients with symptomatic porphyria. In a preliminary report (Sweeney et al., 1962) it was shown that the administration of chloroquine to five of the nine patients was regularly followed by massive uroporphyrinuria without a simultaneous increase in A.L.A. and P.B.G. excretion. In the first two patients a moderately severe constitutional disturbance lasting only 24 hours coincided with maximal uroporphyrinuria. The serum glutamic oxaloacetic transaminase (S.G.O.T.) activity in the second patient reached 1,113 Karmen units; the next three patients showed minor clinical reactions, which were accompanied by levels of S.G.O.T. activity not exceeding 250 Karmen units. The elevation in S.G.O.T. activity was transient, and 
there was no evidence of permanent hepatic damage. Further study was considered important, particularly in view of the claims made for chloroquine as a therapeutic agent in cutaneous porphyria, and the widespread use of 4-aminoquinolines in the treatment of amoebiasis in a population where symptomatic porphyria is also common.

It is suggested that sensitivity to chloroquine is part of the biochemical disturbance manifesting as symptomatic porphyria. The reaction to chloroquine is transient whether administration of the drug is continued or not ; it cannot, therefore, be said to aggravate the disease, nor does it cause acute porphyria in these patients.

\section{Patients and Methods}

Routine biochemical investigations were performed by the department of chemical pathology, using standard methods. Bromsulphthalein excretion: after the administration of $5 \mathrm{mg}$. of dye per $\mathrm{kg}$. of body weight the percentage retained at 45 minutes was determined, up to $6 \%$ retention being accepted as normal.

Porphyrin metabolism was investigated using the following methods: quantitative urine porphyrin (Rimington and Sveinsson, 1950 ; Dresel et al., 1956) ; A.L.A. and P.B.G. (Mauzerall and Granick, 1956); quantitative faecal porphyrin (Holti et al., 1958) ; paper chłomatography (Eriksen, 1953); electrophoresis (With, 1956). Total liver porphyrin was measured as follows. Liver biopsy specimens weighing 5-10 mg. were homogenized in acetone. The acetone was acidified with concentrated $\mathrm{HCl}$ and the tissue residue filtered off. The residue was washed with a little fresh acidified acetone and the washings were added to the filtrate. The combined acidacetone extracts were added to 5 volumes of water, the solution brought to $\mathrm{pH} 3.5$, and the porphyrin extracted into a mixture of $n$-butanol and ethyl acetate in equal parts. The organic extract was washed twice with small volumes of water and porphyrin extracted into $1.5 \mathrm{~N} \mathrm{HCl}$ after the addition of ether. Porphyrin present was measured fluorimetrically, using a coproporphyrin standard. If the quantity of porphyrin permitted, ether-soluble and insoluble fractions were estimated separately, and where possible, after suitable concentration, the porphyrin was identified by chromatography and electrophoresis.

Our experience in Capetown of symptomatic porphyria has included 56 Cape coloured, 38 Bantu, and 14 white patients. The nine patients treated with chloroquine were all males and included seven Cape coloured, one white, and one Bantu. They satisfied the following diagnostic criteria: cutaneous lesions characteristic of porphyria were present ; there was no family history suggestive of porphyria ; urine uroporphyrin was greatly increased, with a normal or only slightly increased excretion of A.I.A. and P.B.G. ; there was a slight-to-moderate increase in the faecal coproporphyrin, which usually exceeded the faecal protoporphyrin; and the hepatic porphyrin was grossly increased.

The nine patients ranged in age from 27 to 59 years. All had consumed excessive quantities of alcohol for many years. Hepatomegaly was an invariable finding, although none showed clinical evidence of cirrhosis. In seven cases the urine contained urobilinogen on admission (qualitative test with Ehrlich's aldehyde reagent), which disappeared within a few days. One case had coincident pyelonephritis and another had mild congestive cardiac failure.

Evidence of liver disease was sought. Serum albumin and globulin and alkaline phosphatase were routinely measured and the flocculation tests (zinc and thymol turbidity) were performed. The serum globulin fraction was consistently elevated $(2.8-4.1$ g. $/ 100 \mathrm{ml}$., mean $3.5 \mathrm{~g} . / 100 \mathrm{ml}$.), and zinc turbidity was 11 units or more in all except two patients. Bromsulphthalein excretion was normal in all cases, as was the serum bilirubin concentration. The prothrombin index was $80 \%$ or less in three cases. S.G.O.T. activity ranged from 20 to 69 Karmen units (mean 32), being below 40 units in all but two cases. Mean values and ranges of porphyrin excretion are given in Table I.

TABLE I.-Porphyrin Excretion and Hepatic Porphyrin Content Before

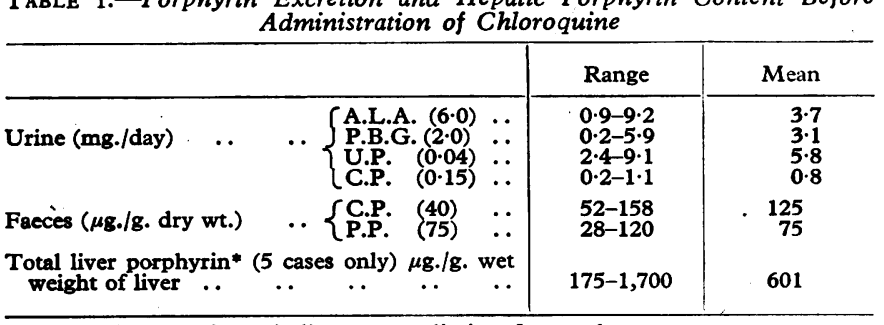

Figures in parentheses indicate upper limits of normal.

Figures in parentheses indicate upper limits of normal. accurate assay. A.L.A. $\overline{\text { p. }}$-Aminolaevulinic acid. P.B.G- $=$ Porphobilin
= Coproporphyrin. P.P. $=$ Protcporphyrin.

Needle biopsy of the liver was performed in each case. When examined in ultra-violet light all specimens were brilliantly fluorescent. Histologically, only one specimen showed frank cirrhosis, but the portal tracts were prominent in all except two, and all showed evidence of active cell-regeneration, indicating a continuing pathological process; four specimens showed septum-formation, and all but one showed fatty change. Increased iron deposition was a consistent finding.

The foregoing description emphasizes that the presentation of these cases was uniform clinically, biochemically, and pathologically.

\section{Plan of Investigation}

The patients studied were in hospital on a standard diet and with one exception were studied in the metabolism ward. Before chloroquine was administered it was explained that the drug might produce a brief illness but that we believed recovery would be prompt and complete, and, furthermore, the release in the urine of a large amount of pigment might be beneficial.

After a control period each patient received a daily dose of chloroquine which varied from 0.125 to $0.5 \mathrm{~g}$. (Table II). The total dose did not exceed $2.5 \mathrm{~g}$., and in five patients was $1 \mathrm{~g}$. or less. Together with close clinical surveillance and serial investigations of liver function, the daily excretion of porphyrins and their precursors was measured before, during, and after the administration of chloroquine.

\section{Symptoms and Signs}

The drug regularly induced a febrile reaction associated with darkening of the urine (see Fig. 1). After a variable latent

TABLE II.-Reaction of Individual Cases to Chloroquine

\begin{tabular}{|c|c|c|c|c|c|c|c|c|c|c|c|}
\hline & & & Case 1 & Case 2 & Case 3 & Case 4 & Case 5 & Case 6 & Case 7 & Case 8 & Case 9 \\
\hline 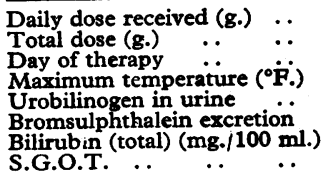 & $\begin{array}{l}\because \\
\because \\
\because \\
\because \\
\therefore\end{array}$ & $\begin{array}{l}\ddot{*} \\
\ddot{*} \\
\ddot{*} \\
\ddot{0}\end{array}$ & $\begin{array}{c}0.5 \\
2.5 \\
3 \\
103 \\
+ \\
\text { Normal } \\
1.3(0.5) \\
-\end{array}$ & $\begin{array}{c}0 \cdot 25 \\
0 \cdot 75 \\
3 \\
101 \cdot 6 \\
+ \\
\text { Normal } \\
7 \cdot 1(0 \cdot 7) \\
-\end{array}$ & $\begin{array}{c}0.25 \\
1 \cdot 0 \\
3 \\
102 \\
- \\
\text { Normal } \\
1.5(0 \cdot 3) \\
1,113(20)\end{array}$ & $\begin{array}{c}0.125 \\
0 \cdot 625 \\
2 \\
101 \\
- \\
\text { Abnormal } \\
1 \cdot 1(0 \cdot 2) \\
230(23)\end{array}$ & $\begin{array}{c}0 \cdot 25 \\
2 \cdot 00 \\
8 \\
102 \cdot 4 \\
- \\
\text { Abnormal } \\
252 \overline{(31)}\end{array}$ & $\begin{array}{c}0.125 \\
1 \cdot 00 \\
2 \cdot 6 \\
99 \cdot 6 \\
- \\
117 \overline{(26)}\end{array}$ & $\begin{array}{c}0 \cdot 25 \\
2 \cdot 00 \\
5 \\
100 \\
- \\
\text { Normal } \\
1.9(0 \cdot 5) \\
165(69)\end{array}$ & $\begin{array}{c}0 \cdot 25 \\
1 \cdot 00 \\
3 \\
100 \cdot 6 \\
+ \\
\text { Abnormal } \\
2 \cdot 6(0 \cdot 4) \\
1,880(24)\end{array}$ & $\begin{array}{c}0.5 \\
1.5 \\
2 \\
102 \cdot 8 \\
+ \\
\text { Normal } \\
1.6(1 \cdot 0) \\
1,400(23)\end{array}$ \\
\hline
\end{tabular}


period of two to eight days a rise in temperature of up to 100 $103^{\circ} \mathrm{F} .\left(37.8-39.4^{\circ} \mathrm{C}\right.$.) occurred (Table II). Chills, headaches, and a feeling of general malaise was usually associated, while in some patients backache and myalgia were present. Anorexia and nausea, with right upper quadrant epigastric or central abdominal pain of moderate intensity, were present in all except two patients. There was no rigidity or rebound tenderness. The fever was mild and evanescent, the symptoms lasting only two to three days whether the drug was withdrawn or not. Urobilinogenuria was noted in four cases. Serial determinations of the E.S.R. (Westergren) in one patient showed a rise from 16 to a maximum of $45 \mathrm{~mm}$. $/ \mathrm{hr}$. on the fourth day after chloroquine administration.
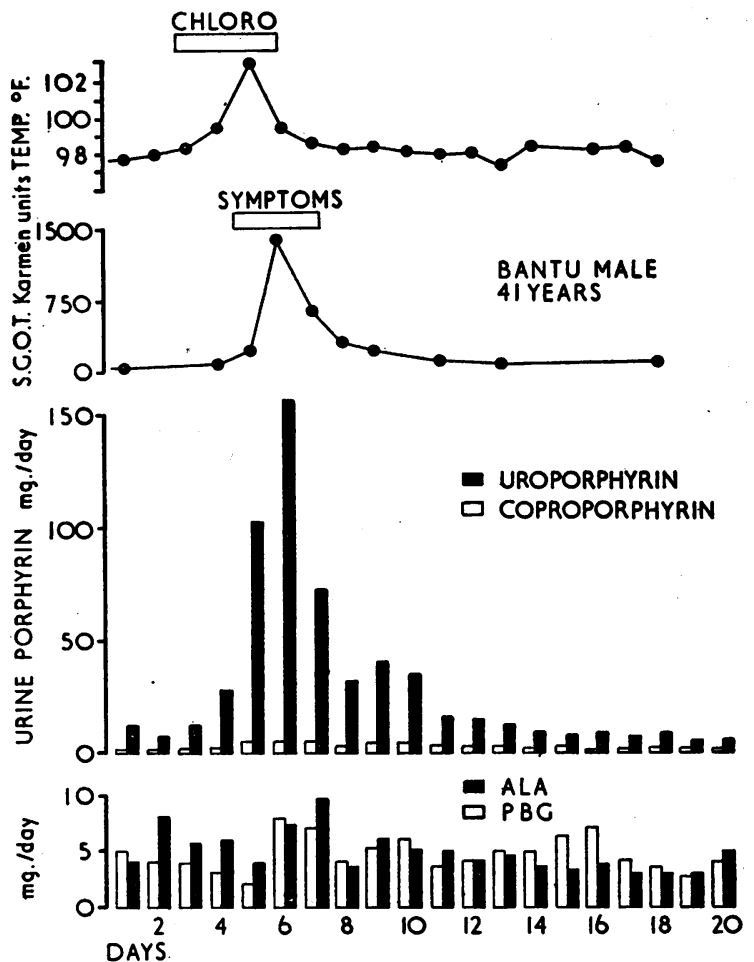

Fig. 1.- Reaction to chloroquine in Case 9. Chloro indicates the period over which $1.5 \mathrm{~g}$. of chloroquine was administered. Symptoms consisted of headache, malaise, abdominal pain, and vomiting.

\section{Hepatic Function}

Clinically the impression was gained that the abdominal pain was, at least in part, due to liver tenderness. Serial determinations of serum bilirubin were made in seven patients : all showed transient increases, but in only two did the maximum level of bilirubin exceed $2 \mathrm{mg} . / 100 \mathrm{ml}$. of serum, in one instance reaching $7.1 \mathrm{mg} . / 100 \mathrm{ml}$. Retention of B.S.P. was noted in three out of seven cases at the height of the response to chloroquine. Serial estimations of S.G.O.T. in seven cases showed highly significant increases in all. The S.G.O.T. activities at the height of the reaction ranged from 177 to 1,880 Karmen units (mean 737 units) (Table II). None of these abnormalities persisted for more than a few days after the reaction to chloroquine, and there was no alteration in the serum proteins or in the flocculation tests of "liver function."

\section{Excretion of Porphyrins and Their Precursors During the Reaction}

Urine.-The excretion of uroporphyrin in the urine reached very high levels, exceeding $80 \mathrm{mg}$. a day in five patients. The increase in urine coproporphyrin was less marked (Table III). Only slight increases occurred in the output of A.L.A. and
P.B.G. Fig. 2 illustrates representative findings and shows the striking rise in uroporphyrin excretion in Case 1. No corresponding increases in faecal porphyrin were observed. Case 3 received initially $1 \mathrm{~g}$. of chloroquine which provoked. massive uroporphyrinuria. When the urine uroporphyrin returned to control levels a further $2 \mathrm{~g}$. of chloroquine was given without effect. Case 4, however, received an initial dose of only

TABLE III.-Excretion of Porphyrins and Porphyrin Precursors at Height TABLE III.-Excretion of Porphyrins and Porphyrin
of Reaction to Chloroquine

\begin{tabular}{|c|c|c|c|c|c|c|}
\hline \multirow{2}{*}{$\begin{array}{l}\text { Case } \\
\text { No. }\end{array}$} & \multicolumn{4}{|c|}{ Urine (mg./day) } & \multicolumn{2}{|c|}{ Faeces ( $\mu \mathrm{g} . / \mathrm{g}$. dry wt$)$} \\
\hline & A.L.A. & P.B.G. & U.P. & C.P. & C.P. & P.P. \\
\hline $\begin{array}{l}1 \\
2 \\
3 \\
4 \\
5 \\
6 \\
7 \\
8 \\
9\end{array}$ & $\begin{array}{l}1.3(0.9) \\
3.8(3.1) \\
2.8 \\
8.6(1.2) \\
4.7(4.3) \\
2.4(3.7) \\
3.3(3.4) \\
4.3(9.2) \\
7.4(5.8)\end{array}$ & $\begin{array}{l}1.0(0.2) \\
1.9(4.5) \\
3.0(2.2) \\
1.6(2.1) \\
4.2(2.7) \\
0 \quad(3.9) \\
1.7(3.2) \\
2.0(3.6) \\
7.0(5.9)\end{array}$ & $\begin{array}{r}81.0(6.4) \\
94.1(7.6) \\
84.5(4.8) \\
37.0(3.7) \\
28.5(2.4) \\
10.3(4.8) \\
16.0(5.1) \\
108.0(9.1) \\
156.0(8.9)\end{array}$ & $\begin{array}{l}3.8(1.1) \\
6.0(0.9) \\
3.7(0.8) \\
2.2(0.7) \\
4.1(0.7) \\
2.2(0.9) \\
1.0(0.2) \\
2.9(1.0) \\
5.8(0.7)\end{array}$ & $\begin{array}{r}84(46) \\
145(105) \\
267(156) \\
25(102) \\
55(70) \\
84(230) \\
135(158) \\
79(52) \\
183(97)\end{array}$ & $\begin{array}{rr}90 & (55) \\
35 & 56 \\
100 & 61) \\
26 & (19) \\
26 & (28) \\
42(120 \\
59(74) \\
114(114) \\
159(86)\end{array}$ \\
\hline
\end{tabular}

Figures in parentheses refer to pretreatment levels.

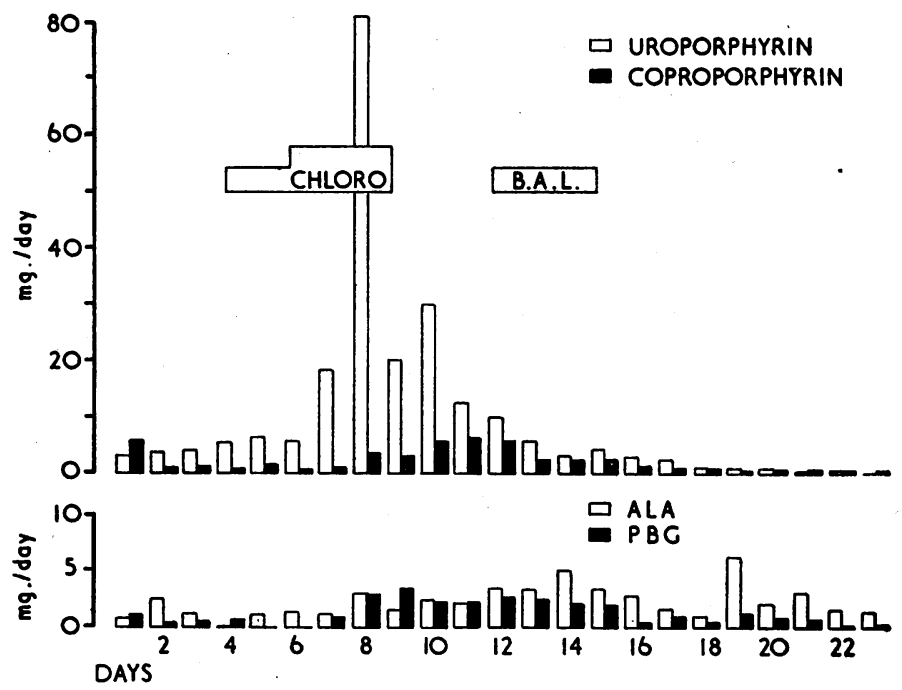

FIG. 2.-Administration of chloroquine to Case 1 caused a marked increase in uroporphyrin excretion. There was no comparable increase in porphyrin precursor excretion. B.A.L. (dimercaprol) was administered because of the profound clinical disturbance, but was probably without effect.

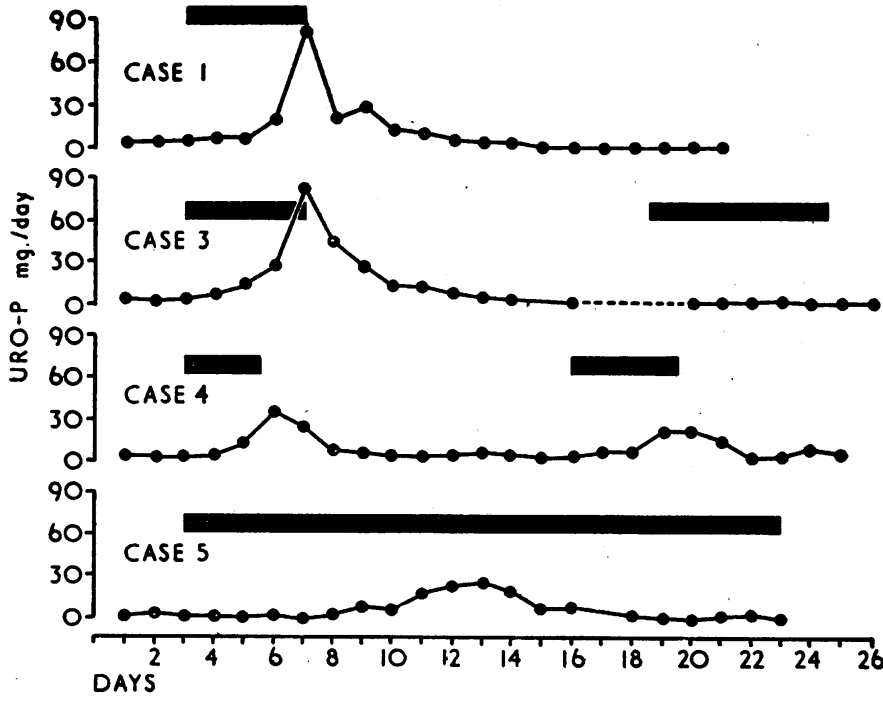

FIG. 3.-Black bars indicate periods of chloroquine administration to four individuals. Cases 1 and 3 show massive uroporphyrinuria following chloroquine. Readministration of the drug was without effect in Case 3, but in Case 4, where the initial dose was small, readministration
again increased uroporphyrin excretion. In Case 5 the response to again increased uroporphyrin excretion. In Case 5 the response to
chloroquine was delayed: the uroporphyrin increased only temporarily despite continued administration of the drug. 
$0.625 \mathrm{~g}$. of chloroquine; a mild clinical reaction accompanied by increased uroporphyrin excretion resulted. In this patient readministration of chloroquine failed to produce a subjective clinical reaction, but the temperature rose and uroporphyrin excretion again increased (Fig. 3 ).

Chloroquine was continued for prolonged periods in Cases 5,6 , and 8 but the reaction remained, nevertheless, a transient phenomenon.

\section{Follow-up Studies}

At periods varying from 18 to 66 months after therapy with chloroquine, eight of the nine patients were seen in hospital or visited at home ; five of these were gainfully employed, and one was a pensioner. Urine porphyrin excretion before treatment and on follow-up is indicated in Table IV. Patients with symptomatic porphyria are advised to abstain from alcohol, and it was important to ascertain whether this advice was being followed. Four patients (Cases 2, 3, 5, and 8) had not changed their drinking habits, and no material change was evident in porphyrin excretion. Four patients (Cases 1, 6, 7, and 9) showed a significant decrease in porphyrin excretion; two of these (Cases 1 and 7) had abstained from taking alcohol, in the other two doubt remained. It is concluded that the decrease in porphyrin excretion evident in Cases $1,6,7$, and 9 is due to abstinence from alcohol, and that treatment with chloroquine exerts no long-term beneficial effect in symptomatic porphyria.

TABLE IV.-Follow-up Studies of Porphyrin Excretion

\begin{tabular}{|c|c|c|c|c|c|c|c|c|}
\hline Case No.: & 1 & 2* & $3^{*}$ & $5 *$ & 6 & 7 & $8^{*}$ & 9 \\
\hline $\begin{array}{l}\text { Duration of follow-up } \\
\text { (months) } \ddot{0} \text {. } \\
\text { Urine porphyrin excre- }\end{array}$ & 66 & 30 & 36 & 21 & 34 & 32 & 20 & 18 \\
\hline $\begin{array}{l}\text { Uro- } \\
\text { porphyrin }\left\{\begin{array}{l}\text { Before } \\
\text { After }\end{array}\right.\end{array}$ & $\begin{array}{l}4.00 \\
0.11\end{array}$ & $\begin{array}{l}6 \cdot 10 \\
5 \cdot 84\end{array}$ & $\begin{array}{l}3 \cdot 40 \\
3.33\end{array}$ & $\begin{array}{l}2.40 \\
1.32\end{array}$ & $\begin{array}{l}4.50 \\
0.98\end{array}$ & $\begin{array}{l}2.90 \\
0.41\end{array}$ & $\begin{array}{l}12 \cdot 20 \\
10.22\end{array}$ & $\begin{array}{l}3.80 \\
0.60\end{array}$ \\
\hline $\begin{array}{l}\text { Copro- } \\
\text { porphyrin }\end{array}\left\{\begin{array}{l}\text { Before } \\
\text { After }\end{array}\right.$ & $\begin{array}{l}0.90 \\
0.12\end{array}$ & $\begin{array}{l}0.50 \\
0.74\end{array}$ & $\begin{array}{l}0.80 \\
0.33\end{array}$ & $\begin{array}{l}0.20 \\
0 \cdot 30\end{array}$ & $\begin{array}{l}1 \cdot 30 \\
0 \cdot 38\end{array}$ & $\begin{array}{l}0.20 \\
0 \cdot 15\end{array}$ & $\begin{array}{l}1 \cdot 80 \\
1 \cdot 30\end{array}$ & $\begin{array}{l}0.40 \\
0.052\end{array}$ \\
\hline
\end{tabular}

*Indicates continued abuse of alcohol.

\section{Discussion}

\section{Toxic Effects of Chloroquine}

Initial studies of the toxic effects of chloroquine were made before the drug was introduced as an antimalarial agent (Alving et al., 1948), and further experience in the effects of long-term therapy with chloroquine has been gained during the treatment of lupus erythematosus and rheumatoid arthritis. The less serious reactions (Kautz, 1959) include headache, pruritus, visual disturbances, and gastro-intestinal complaints. Skin reactions are frequent, and include dryness, urticaria, maculopapular eruptions, and exfoliation. Corneal oedema and opacities, and leucopenia are serious effects. Acute and sometimes fatal toxic reactions have been reported in children (Cann and Verhulst, 1961), but the emphasis in these reactions has been on the quinidine-like effects of the drug which have led to cardiac or respiratory arrest. These are all very different from the acute reversible reaction we describe.

Experimental work in animals has shown that the 4-aminoquinoline drugs are rapidly and completely absorbed from the gastro-intestinal tract and are selectively concentrated in the liver, spleen, kidneys, and lungs (Berliner et al., 1948); the same may happen in man, since an intravenous dose is rapidly cleared from the plasma, while only $10-20 \%$ is excreted in the urine. This may explain why the liver is affected by such small doses of the drug.

Cripps and Curtis (1962) reported that no alteration in porphyrin excretion followed administration of chloroquine to normal persons or to 12 patients with discoid lupus erythematosus.

\section{Adverse Reaction in Symptomatic Porphyria}

In this type of porphyria chloroquine has regularly produced a transient febrile reaction with a coincident gross increase in uroporphyrin excretion but without a significant increase in P.B.G. excretion. Liver tenderness, and in one patient jaundice, suggested clinically that the liver was particularly involved in this reaction, and this view was supported by biochemical studies.

A rise in the S.G.O.T. activity occurred in the seven cases in which this enzyme was measured; in two cases the rise was to between 1,000 and 2,000 units. In only one case did the serum bilirubin rise markedly, but small increases were regularly encountered. There was no evidence of haemolysis. Urobilinogenuria (qualitative testing) accompanied the reaction in four cases, and in three cases there was abnormal retention of bromsulphthalein.

The reaction was variable in intensity. Further administration of chloroquine was without effect except in one patient who received initially only $0.625 \mathrm{~g}$. of the drug. It is not known for how long this refractory state persists.

\section{Analogy Between this Reaction to Chloroquine and Drug-induced Haemolysis}

The 8-aminoquinoline derivative, primaquine, and various other drugs, cause haemolysis in individuals whose erythrocytes are deficient in glucose-6-phosphate dehydrogenase. The acute haemolytic episode follows after a latent period of a few days. Readministration of the drug immediately after haemolysis is without effect.

Similarities of this phenomenon to the chloroquine reaction include the latent period, the small dose of the drug required to provoke the response, and the ensuing refractory state. There is, however, no evidence yet of a comparable enzyme defect in the liver cells of patients with symptomatic porphyria.

\section{Source of Excreted Uroporphyrin.}

Normal human liver obtained at laparotomy was found to contain about $1 \mu \mathrm{g}$. of porphyrin per gramme of liver tissue. In our patients with symptomatic porphyria values of between 100 and 1,000 times this figure were found (Table I). Chromatography and electrophoresis in four cases has shown this liver porphyrin to be largely uroporphyrin and 7-carboxyl porphyrin, and to resemble closely in composition the porphyrin excreted in the urine after administration of chloroquine. The massive uroporphyrinuria is unaccompanied by increased excretion of A.L.A. and P.B.G., and the urine, which is red when voided, does not darken on standing. These facts indicate that the formation of the porphyrin from P.B.G. has occurred neither in the urinary tract nor subsequent to voiding. The most probable source of the excreted uroporphyrin is the liver, from which it is released during the reaction to chloroquine.

\section{Clinical Implications of this Study}

All patients improved clinically while in hospital, but this was attributable to good diet, attention to the skin lesions, and above all to the avoidance of alcohol and protection from sun and trauma. These studies provide little evidence that the clinical improvement following mobilization of the excess hepatic porphyrin materially affects the course of the disease.

Despite the claims for the beneficial effects of chloroquine therapy, we believe that the regular finding of transient but unequivocal signs of liver damage is an argument against the use of this drug in the treatment of symptomatic porphyria. Awareness of this reaction is important in countries like South Africa, where there is a high incidence of both hepatic amoebiasis and symptomatic porphyria. 


\section{Summary}

The administration of chloroquine to patients with symptomatic porphyria causes a transient reaction in which pyrexia and malaise are accompanied by a marked increase in urine porphyrin excretion. The excretion of porphyrin precursors, $\delta$-aminolaevulinic acid and porphobilinogen increases only slightly.

This reaction is associated with clinical and biochemical evidence of liver damage, in particular, a rise in serum glutamic oxaloacetic transaminase activity. It is thought that the porphyrin excreted in the urine is released from the liver.

After the reaction patients are not affected by further administration of chloroquine; it is not known for how long this refractory state persists. The reaction resembles in some ways the primaquine-induced haemolysis of red cells deficient in glucose-6-phosphate dehydrogenase.

Patients with symptomatic porphyria have improved clinically after chloroquine therapy, but this is attributed to other factors; evidence of hepatic dysfunction argues against the use of chloroquine in this condition.

We are indebted to Dr. C. J. Uys, of the department of histopathology, University of Capetown, for examining the liver biopsies, and to the department of chemical pathology for routine chemicopathological data. The assistance of Mrs. M. J. Levey in the estimation of quantitative porphyrins in urine and faeces is gratefully acknowledged.
This work was supported in part by a grant, P.H.S. A-3997, from the National Institute of Arthritis and Metabolic Diseases, Public Health Service, U.S.A. It formed part of the programme of the C.S.I.R./U.C.T. Renal-Metabolic Research Group.

\section{REPERENCES}

Alving, A. S., Eichelberger, L., Craige, B., Jones, R., Whorton, C. M., and Pullman, T. N. (1948), 7. clin. Invest., Suppl. to vol. 27, p. 60 . Berliner, R. W., Earle, D. P, Taggart, J. V., Zubrod, C. G., W Welch, W. J., Conan, N. J., Bauman, E., Scudder, S. T., and Shannon, J. A. (1948). Ibid., p. 98.

Cann, H. M., and Verhulst, H. L. (1961). Pediatrics, 27, 95.

Cripps, D. J., and Curtis, A. C. (1962). Arch. Derm., 86, 575.

Dresel, E. I. B., Rimington, C., and Tooth, B. E. (1956). Scand. 7. clin. Lab. Invest., 8, 73 .

Eales, L. (1961). Ann. Rev. Med., 12, 251.

- Dowdle, E. B., and Sweeney, G. D. (editors) (1963). Proceedings of the International Conference on the Porphyrias, S.A. F. Lab. clin. Med., 9, 301 .

Embree, P. W. (1961). Cent. Afr. F. med., 7, 450.

Eriksen, L. (1953). Scand. .. clin. Lab. Invest., 5, 155.

Holti, G., Rimington, C., Tate, B. C., and Thomas, G. (1958). Quart. 7. Med., 27, 1 .

Kautz, H. D. (1959). f. Amer. med. Ass., 171, 1504.

Linden, I. H., Steffen, C. G., Newcomer, V. D., and Chapman, M. (1954). Calif. Med., 81, 235 .

Mauzerall, D., and Granick, S. (1956). 7. biol. Chem., 219, 435.

Rimington, C., and Sveinsson, S. L. (1950). Scand. F. clin. Lab. Invest., 2, 209.

Sweeney, G. D., Levey, M., Dowdle, E. B., and Eales; L. (1962). S. Afr. Med. 7., 36, 312 .

Teodorescu, S., Badaniou, A., and Gheorghiu, G. (1959). Derm. Wschr., $139,445$.

With, T. K. (1956). Scand. 7. clin. Lab. Invest., 8, 113.

Woods, S. M., Peters, H. A., and Johnson, S. A. M. (1958). Arch. Derm., 77, 559.

\title{
Significance of the Extensor Plantar Response in Surgery of Parkinson's Disease
}

\author{
A. G. L. CORKILL,* M.A., M.B., B.CHIR. ; A. H. CHIGNELL,* M.B., B.S.
}

Brit. med. F., 1965, 1, 1285-1286

Parkinsonian patients showing an extensor plantar response rather than a flexor plantar response are often regarded as having more widespread disease. This is true in that the pyramidal system is being secondarily involved. That a worse prognosis is thereby indicated is, however, not so certain. Nevertheless, the presence of extensor plantar responses is often cited as a relative contraindication to surgery.

The supposed grounds for contraindication appear to be twofold: firstly, patients with extensor plantar responses are thought to have a relatively worse prognosis in any case owing to the more widespread disease, and, secondly, there is a special danger-that of pseudobulbar palsy.

Damage to the internal capsule or other parts of the pyramidal system is an unavoidable occurrence in a small proportion of operative procedures for Parkinsonism. It is supposed that cases already showing involvement of the pyramidal system, as evidenced by extensor plantar responses, will be especially prone to developing pseudobulbar palsy.

It has been observed that a certain number of Parkinsonian patients with extensor plantar responses have concomitant cervical spondylosis or encephalitis (Brain, 1962).

To examine the post-operative prognosis of patients with and without extensor plantar responses who also had widespread

* The National Hospital for Nervous Diseases, Queen Square, London. manifestations of the disease was the purpose of the present review.

\section{Present Investigation}

Clinical Material.-A group of 112 Parkinsonian patients were reviewed, representing all the cases considered as inpatients for operation by Mr. Harvey Jackson at the National Hospital, Queen Square, in the years 1959 to 1961. Of these 112 , 38 were abstracted on the basis of showing widespread manifestations of Parkinson's disease. The remaining 74 patients, who as a group were generally less affected with Parkinsonism, are not further considered here. Widespread manifestations of Parkinson's disease were taken arbitrarily to be, in addition to tremor and rigidity of all four limbs, at least two of the following features: poor voice and speech change, facial akinesia, poor convergence, chairborne existence, tremor of midline structures-that is, jaw, tongue, head, or trunk-and oculogyric crises. Of the 38 patients showing widespread manifestations of the disease, eight had extensor plantar responses on one side and seven had bilateral extensor plantar responses. All 38 were operated on.

Operative Treatment.-This involved the making of a lesion under radiological and electro-stimulatory control in the ventrolateral nucleus of the thalamus. A stiff paste of Etopalin and 